Check for updates

Cite this: RSC Adv., 2017, 7, 37095

Accepted 13th July 2017

DOI: 10.1039/c7ra05535h

rsc.li/rsc-advances
Received 16th May 2017

\section{Theoretical study on the reaction of triallyl isocyanurate in the UV radiation cross-linking of polyethylene}

\author{
Hong Zhao, ${ }^{\text {a }}$ Junqi Chen, ${ }^{a}$ Hui Zhang, (D) *a Yan Shang, ${ }^{a}$ Xuan Wang, \\ Baozhong Han ${ }^{\star a b}$ and Zesheng $\mathrm{Li}$ (D) ${ }^{\mathrm{c}}$
}

\begin{abstract}
Herein, a theoretical investigation on the reaction of triallyl isocyanurate (TAIC) in the UV radiation crosslinking process of polyethylene is conducted at the B3LYP/6-311+G(d,p) level for the production of high voltage cable insulation materials, where the reaction potential energies of 10 reaction channels are identified. The HOMO-LUMO energy gaps, ionization potentials, and electron affinities of the raw materials, product, and by-product in polyethylene insulation composite products are obtained. Furthermore, the optimized process for the production of UV radiation cross-linking polyethylene insulation materials for high voltage cables is described. The results indicate that the UV radiation crosslinking reaction of polyethylene is initiated by benzophenone, and the multi-functional cross-linker TAIC is required for the cross-linking process to occur. This investigation is expected to provide reliable information for the optimization of the polyethylene UV radiation cross-linking process and the development of insulation materials for high-voltage cables that can withstand more than $500 \mathrm{kV}$ in real applications.
\end{abstract}

\section{Introduction}

Cross-linked polyethylene (XLPE) has been widely applied for high voltage cable insulation materials due to its excellent electrical and mechanical properties. The peroxide crosslinking reaction is the traditional process used for the synthesis of high voltage polyethylene cable insulation; however, this process has various disadvantages (e.g., slow production speed, high energy consumption, pre-cross-linking of the material on the surface of the extrusion die during long production periods). The ultra-violet (UV) radiation crosslinking process may become a candidate for the fabrication of the high voltage cable material XLPE. ${ }^{1-6}$ With the aid of a photoinitiator, UV energy can easily penetrate the insulation wall and induce cross-linking when the insulating wall is transparent because polyethylene crystals melt after heating by extrusion. The advantages of UV crossing compared to the traditional process include fast processing speed, small radiation zone, energy saving, and the production is not thermosensitive. Experimental investigations have shown that the rate of the UV

\footnotetext{
${ }^{a}$ Key Laboratory of Engineering Dielectrics and Its Application of Ministry of Education, College of Chemical and Environmental Engineering, Harbin University of Science and Technology, Harbin, 150080, People's Republic of China. E-mail: hongzhao@hrbust. edu.cn; hust_zhanghui11@hotmail.com; hbzhlj@163.com

${ }^{b}$ Shanghai Qifan Cable Co., Ltd., Shanghui, 200008, P. R. China

${ }^{c}$ Key Laboratory of Cluster Science of Ministry of Education, School of Chemistry, Beijing Institute of Technology, Beijing, 100081, P. R. China
}

radiation cross-linking reaction is not only influenced by power, radiation spectrum of the mercury lamp, and UV light emitting diode (LED) hybrid system, but also the type and content of photoinitiator and crosslinker. ${ }^{4-6}$ With the use of the multifunctional crosslinker triallyl isocyanurate (TAIC), the crosslinking process of polyethylene via UV radiation can be as fast as milli-seconds, whereas the crosslinking rate is only on the minute timescale with the use of only photoinitiator. However, the reaction mechanism of polyethylene cross-linking via UV radiation at the atomic and molecular levels are not very clear thus far, particularly with the use of a crosslinker. Therefore, to elucidate the chemical reactions occurring during the UV radiation cross-linking of polyethylene for the development of insulation wall materials for high voltage cables, the role played by the crosslinker should be clearly understood.

Under a high and divergent electric field, partial discharge and insulation failure are often initiated by electrical treeing. ${ }^{7,8}$ The rated voltage of XLPE insulated power cables is limited to $500 \mathrm{kV}$ even though XLPE is manufactured with super-clean technology. Research has shown that some organic polycyclic aromatic compounds or those with benzophenone-like structures, which serve as voltage stabilizers, can increase the resistance to electrical treeing effectively. ${ }^{9-15}$ Using theoretical studies, our group first elucidated the mechanisms of aromatic carbonyl compounds as voltage stabilizers for increasing the electrical breakdown strength of XLPE in $2013 .{ }^{16-18}$ Acetophenone is an example of an aromatic carbonyl compound that can function as a voltage stabilizer; however, it easily migrates out of 
the polymeric matrix. Thus, aromatic carbonyl and benzil-type compounds with a larger alkoxy chain can effectively increase the compatibility with the polyethylene matrix and improve the electrical treeing inception level significantly. ${ }^{\mathbf{1 3 4} \mathbf{1 4}}$ This inspired us to investigate if polyethylene chains can be grafted with voltage stabilizer molecules to yield stationary products during the UV radiation cross-linking process for the fabrication of XLPE insulation materials possessing permanent insulation performances.

What type of reactions occur between the photoinitiator and multi-functional crosslinker with polyethylene in the UV radiation cross-linking process and is it possible that the voltage

Table 1 Molecular formula, molecular name, and corresponding abbreviation of the studied molecules

Molecular formula

<smiles>CC(=O)c1ccccc1</smiles>

O<smiles>CCCCC(=O)c1ccccc1</smiles>

Valerophenone

Benzophenone

$\mathrm{B} z$

2,6-Di-t-butyl-4- $n$-butylphenol

1,3,5-Triallyl isocyanurate

1,1,2,2-Tetraphenyl-1,2-ethanediol
$\mathrm{Ab}$.

$\mathrm{Pe}$

Ap

Vp<smiles>CCCC(C)CCC</smiles>

Bp<smiles>CCCCC(=O)c1ccccc1</smiles>

TAIC

PBz

PTAIC

PTAIC1
Pe2

Vp4<smiles>CCCCC(=O)c1ccccc1</smiles>

Vp3<smiles>CCCCC(=O)c1ccccc1</smiles>

Vp2

Ab.

Pe4

Pe3 4 3<smiles>CCCCc1cc(C(C)(C)C)c(O)c(C(C)(C)C)c1</smiles>

Bp4

Bp3

Bp2<smiles>OC(c1ccccc1)c1ccccc1</smiles> 
stabilizer or antioxidant molecules graft to the polyethylene molecule chain?

The reactions in the UV radiation cross-linking process have been investigated using density functional theory (DFT),${ }^{19}$ where the possibilities of voltage stabilizer grafting have been studied. Generally, the main materials for the preparation of XLPE are cross-linkable polyethylene, benzophenone $(\mathrm{Bz})$ photoinitiator, hindered phenol antioxidant, voltage stabilizer, and the multi-functional crosslinker triallyl isocyanurate (TAIC). In this study, three molecules, 4-methylheptane (Pe), valerophenone (Vp), and 2,6-di-t-butyl-4-nbutylphenol (Bp), are selected as model molecules for crosslinkable polyethylene, voltage stabilizer, and antioxidant, respectively. The molecular formula, molecular name, and corresponding abbreviations of the studied molecules are listed in Table 1. The spin-orbit couplings are taken into account to clarify the mechanism of the $\mathrm{S}_{1} \rightarrow \mathrm{T}_{1}$ decay, which were investigated experimentally. ${ }^{20-24}$ The lowest excited singlet state is $\mathrm{S}_{1}\left(\mathrm{n}, \pi^{*}\right)$, which originates from the $\mathrm{S}_{1}\left(\mathrm{n}, \pi^{*}\right)$ $\leftarrow \mathrm{S}_{0}$ transition of $26180 \mathrm{~cm}^{-1}(3.25 \mathrm{eV})$. The origin of the first triplet state $\mathrm{T}_{1}\left(\mathrm{n}, \pi^{*}\right) \leftarrow \mathrm{S}_{0}$ is at $24224 \mathrm{~cm}^{-1}(3.00 \mathrm{eV}){ }^{25}$ Fang and co-workers ${ }^{26}$ theoretically discovered the existence of the $S_{1} / T_{2} / T_{1}$ intersection, which results in $S_{1} \rightarrow T_{1}$ intersystem crossing taking place at a high rate. This is the reason why aromatic carbonyl compounds are highly phosphorescent. In this study, the benzophenone-initiated chemical reactions in the UV radiation cross-linking process are investigated only at the lowest triplet state.

To the best of our knowledge, no theoretical study has addressed the role played by TAIC in the UV radiation crosslinking process at the atomic and molecular levels. Herein, we aim at providing a systematic investigation on the possible reactions taking place during the benzophenone initiation of radical polyethylene molecules and the TAIC multiplication and acceleration of cross-linking during the polyethylene UV radiation cross-linking process in the presence of a voltage stabilizer and antioxidant. The UV radiation cross-linking reaction mechanism is proposed on the basis of a theoretical study,

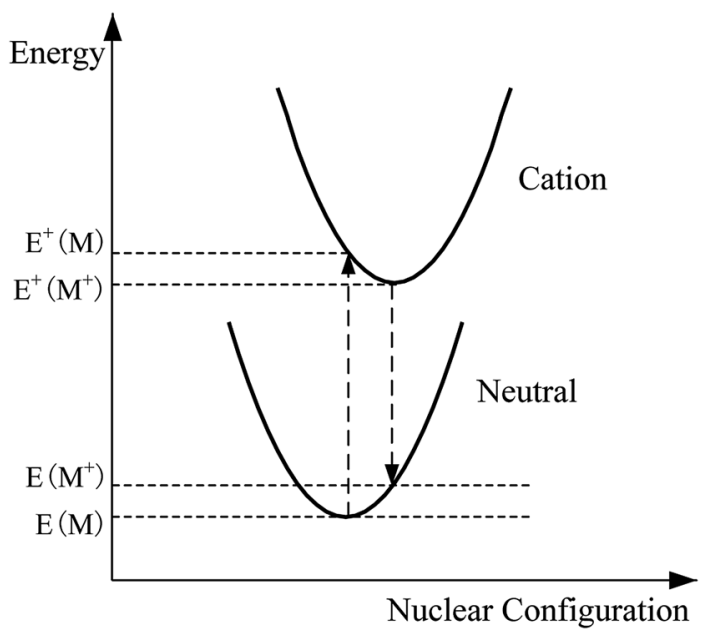

Fig. 1 Schematic of the geometric coordinate modifications and energy changes. which would be useful for the rational molecular design of additives and the optimization of the UV radiation cross-linking process for real applications.

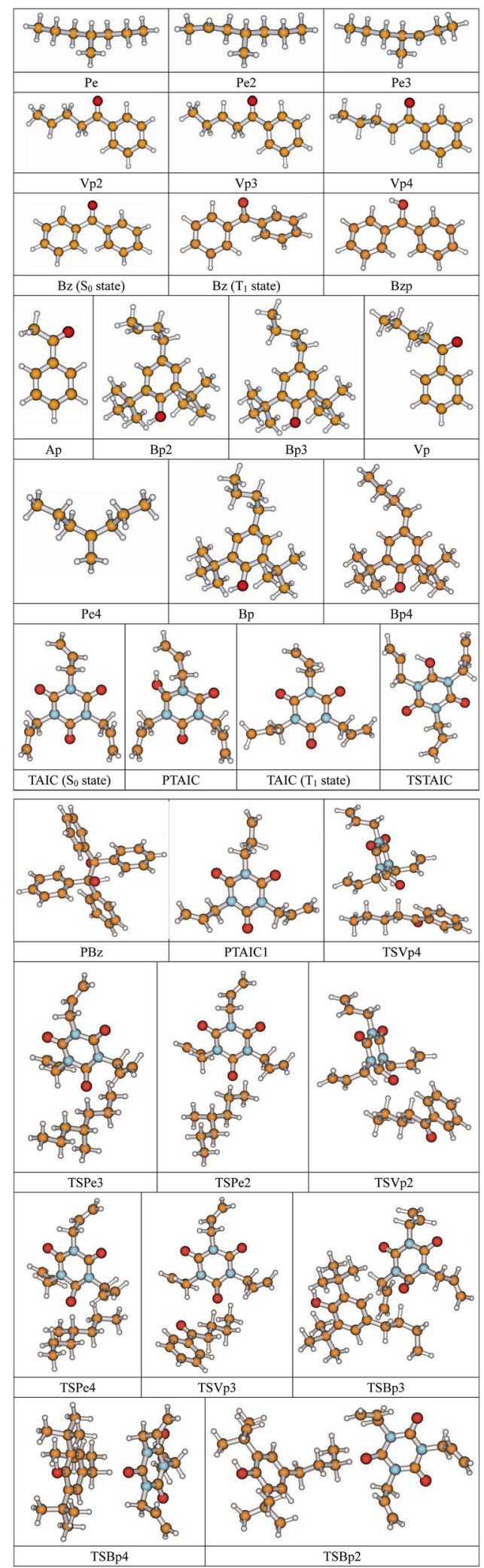

Fig. 2 Optimized geometric structures of the studied molecules at the B3LYP/6-311+G(d,p) level. 
Table 2 Optimized bond lengths of broken/formed bonds $(\mathrm{b} / \mathrm{f})$ for the transition states, and the corresponding reactant bonds, product bonds (all in angstroms), and calculated broken/formed bond frequencies (in $\mathrm{cm}^{-1}$ ) at the $T_{1}$ state at the B3LYP/6-311+G(d,p) level of the 9 reaction channels, and the reaction channel forming PTAIC1 at the $S_{0}$ state

Reaction equation $\quad$ Reactant b/f Product<smiles></smiles><smiles></smiles><smiles></smiles><smiles>C=CCN1C(=O)N(CC=C)C(=O)N(CC=C)N(CC=C)C1=O</smiles><smiles>C=CCN1C(=O)N(CC=C)C(=O)N(CC=C)N(CC=C)C1=O</smiles><smiles>C=CCN1C(=O)N(CC=C)C(=O)N(CC=C)N(CC=C)C1=O</smiles><smiles>C=CCN1C(=O)N(CC=C)C(=O)N(CC=C)N(CC=C)C1=O</smiles><smiles></smiles>

1.100

$1.187 / 1.492$

0.950

1.098

1.097

1.098

$1.220 / 1.390$

0.950

$806 \mathrm{i}$

1.095

$1.214 / 1.403$

0.950

$658 \mathrm{i}$

1.097

$1.197 / 1.428$

0.950

$463 \mathrm{i}$

1.096

$1.269 / 1.407$

0.950

$2176 \mathrm{i}$

1.097

$1.201 / 1.416$

0.950

$561 \mathrm{i}$ 
Reaction equation

Reactant

$\mathrm{b} / \mathrm{f}$

Product

Freq.
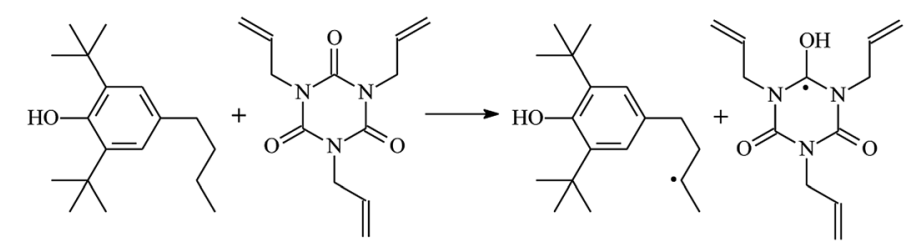

1.098

$1.187 / 1.455$

0.950

$301 \mathrm{i}$

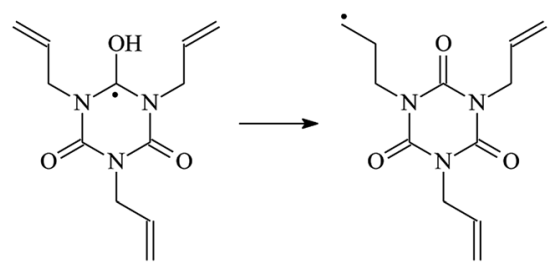

0.968

$1.148 / 1.497$

1.093

$2103 \mathrm{i}$

\section{Computational methods}

The equilibrium geometries of the reactants and products in the neutral and ion states were optimized at the ground state using the B3LYP ${ }^{27-30}$ functional with the $6-311+G(d, p)$ basis set, including the stationary points for the formation of the PTAIC1 reaction channel, except for the stationary points of the 9 reaction channels in their triplet state. In this study, the frequencies are also calculated using the same method. On the basis of these calculations, the energy gap $\left(E_{\mathrm{g}}\right)$ between the highest occupied molecular orbital (HOMO) and the lowest unoccupied molecular orbital (LUMO), the ionization potential (IP), and the electron affinity (EA) are obtained. The minimum energy path (MEP) is obtained by intrinsic reaction coordinate (IRC) theory with a gradient step-size of 0.05 (amu $)^{1 / 2}$ bohr. Then, the first and second energy derivatives are obtained to calculate the curvature of the reaction path and the generalized vibrational frequencies along the reaction path. All the electronic structure calculations are performed using GAUSSIAN09 program package. ${ }^{31}$ The relevant schematic formulae can be defined as follows: $\mathrm{IP}(\mathrm{v})=E^{+}(\mathrm{M})-E(\mathrm{M}) ; \mathrm{IP}(\mathrm{a})=E^{+}\left(\mathrm{M}^{+}\right)-E(\mathrm{M})$; $\mathrm{EA}(\mathrm{v})=E(\mathrm{M})-E^{-}(\mathrm{M}) ; \mathrm{EA}(\mathrm{a})=E(\mathrm{M})-E^{-}\left(\mathrm{M}^{-}\right)$, where $E^{+}\left(\mathrm{M}^{+}\right)$, $E^{-}\left(\mathrm{M}^{-}\right)$, and $E(\mathrm{M})$ represent the energies of the cation, anion and neutral species in their lowest energy geometries, respectively; $E^{+}(\mathbf{M})$ and $E\left(\mathbf{M}^{+}\right)$refer to the energies of cation and neutral species with the geometries of neutral and cation, respectively; $E^{-}(\mathrm{M})$ and $E\left(\mathrm{M}^{-}\right)$are the energies of anion and neutral species with the geometries of neutral and anion, respectively, $\mathrm{v}$ and a represent the vertical energy based on the geometry of the neutral molecule and adiabatic energy from the optimized structure for both the neutral and charged molecule, respectively. A schematic of the geometric coordinate modifications and energy changes is given in Fig. 1.

\section{Results and discussion}

\subsection{Stationary point geometries}

The optimized geometric structures at the first triplet state $\mathrm{T}_{1}$ of the reactants and transition states of the 9 TAIC cross-linked reactions at the $\mathrm{B} 3 \mathrm{LYP} / 6-311+\mathrm{G}(\mathrm{d}, \mathrm{p})$ level and the reaction channel forming PTAIC1 at the ground state $\mathrm{S}_{0}$ are presented in Fig. 2. In addition, the other optimized equilibrium geometries of the stationary points at the ground state are presented in Fig. 2. The optimized bond lengths of the broken and formed bonds for the 10 transition states, the corresponding reactant $\mathrm{C}-\mathrm{H}$ bonds, and the product $\mathrm{O}-\mathrm{H}$ bond, and the calculated corresponding harmonic vibrational frequencies are listed in Table 2. The chemical reaction equations of the possible TAIC cross-linked reactions in the upper cross-linking production processes are included. All the transition states are confirmed by normal-mode analysis to have only one imaginary frequency corresponding to the stretching modes of the coupled broken and formed bonds. The other harmonic vibrational frequencies are confirmed by normal-mode analysis to have real frequency. The transition states are abbreviated as the corresponding TS and the reaction channels are represented as $\mathrm{R}$. In Table 2 , it can be seen that the transition state structures at the $T_{1}$ state of the 9 studied hydrogen abstraction reactions have a common character. The elongation of the $\mathrm{C}-\mathrm{H}$ broken bonds in the $\mathrm{Pe}$, $\mathrm{Vp}$, and Bp model molecules is smaller than that of the corresponding formed $\mathrm{O}-\mathrm{H}$ bond in equilibrium PTAIC, which indicates that these hydrogen abstraction reactions are all reaction-like, i.e., the reaction pathways will proceed via "early" transition states.

\subsection{Energies: frontier MOs, IPs, and EAs}

The IP and EA of a molecule are important parameters to estimate the capacity for its reduction and oxidation, respectively. Table 3 lists the calculated values of the vertical and adiabatic IPs and EAs at the B3LYP/6-311+G(d,p) level and the corresponding experimental data $^{32}$ (in bracket), as well as the calculated HOMO-LUMO energy gap $\left(E_{\mathrm{g}}\right)$. The B3LYP//6$311+\mathrm{G}(\mathrm{d}, \mathrm{p})$ level was confirmed to be suitable for the current study since the computational values of the adiabatic ionization potentials IP(a) and the electron affinities EA(a) at this level are in agreement with the corresponding experimental values in our previous study, ${ }^{33}$ which indicates that the theoretical results 
Table $3 E_{\mathrm{g}}$ IPs, and EAs of the studied molecules (in eV) calculated at the B3LYP/6-311+G(d,p) level at the ground state as well as the corresponding experimental data in brackets

\begin{tabular}{|c|c|c|c|c|c|c|}
\hline Ab. & Molecular formula & $E_{\mathrm{g}}$ & $\mathrm{IP}(\mathrm{a})$ & $\mathrm{IP}(\mathrm{v})$ & $\mathrm{EA}(\mathrm{a})$ & $\mathrm{EA}(\mathrm{v})$ \\
\hline $\mathrm{Pe}$ & & 8.38 & 9.41 & 10.03 & -1.09 & -1.10 \\
\hline Ap & & 5.20 & $8.95(9.10 \pm 0.10)$ & 9.19 & $0.33(0.33)$ & 0.09 \\
\hline $\mathrm{Vp}$ & & 5.19 & 8.79 & 8.94 & 0.33 & 0.15 \\
\hline Вр & & 5.62 & 7.20 & 7.49 & -0.73 & -0.74 \\
\hline $\mathrm{Bz}$ & & 4.90 & $8.64(9.05)$ & 8.67 & $0.73(0.69 \pm 0.05)$ & 0.50 \\
\hline $\mathrm{PBz}$ & & 5.39 & 7.56 & 7.72 & -0.03 & -0.24 \\
\hline TAIC & & 6.90 & 8.55 & 9.05 & -0.26 & -0.55 \\
\hline PTAIC & & 4.16 & 5.00 & 6.91 & 1.26 & 0.25 \\
\hline PTAIC1 & & 5.24 & 6.23 & 8.30 & 0.38 & 0.15 \\
\hline
\end{tabular}

herein are reasonable and reliable. The varied trends of the IP and EA are similar to that for the negative value of the corresponding HOMO and LUMO energies, respectively. In Table 3, it can be seen that $E_{\mathrm{g}}$ depends on the energy difference between the $\sigma$ and $\sigma^{*}\left(\sigma \rightarrow \sigma^{*}\right)$ orbitals in the carbon chain, $E_{\mathrm{g}}$ decreases with an increase in the carbon chain length and the values of $E_{g}$ $(\mathrm{Vp}, 5.19 \mathrm{eV})$ are lower than those of Ap. The introduction of phenyl or heteroatom groups into the molecule are propitious for electronic dissociation because of the high HOMO energy levels and small ionization potentials in terms of Koopmans' theorem, where the $E_{\mathrm{g}}$ value is the energy gap of $\pi \rightarrow \pi^{*}$. Thus,
$E_{\mathrm{g}}(\mathrm{Bz}, 4.90 \mathrm{eV})<E_{\mathrm{g}}(\mathrm{Ap}, 5.20 \mathrm{eV})<E_{\mathrm{g}}(\mathrm{Pe}, 8.38 \mathrm{eV})$. In addition, $\pi-\pi-\pi$ conjugated effects are present between the carbonyl groups and benzene rings in $\mathrm{Bz}$, and the conjugated system in $\mathrm{Bz}$ is larger than that of Ap. As a result, it can also be concluded that $E_{\mathrm{g}}(\mathrm{Bz})<E_{\mathrm{g}}(\mathrm{Ap})$. The energy of the electronic transition is lower when $E_{\mathrm{g}}$ decreases. Carbonyl is an electron-withdrawing group and $-\mathrm{OH}$ is an electron-donating group, and thus the electron density on the benzene ring in Bp is larger than that of $\mathrm{Vp}$, resulting in weaker electron accepting ability in Bp than that in Vp, where EA (Bp, -0.73) < EA (Vp, 0.33). Similarly, EA (PBz, $-0.03)<\mathrm{EA}(\mathrm{Bz}, 0.73)$. These conjugated aromatic carbonyl or 
Table 4 The reaction enthalpies at $298 \mathrm{~K}\left(\Delta H_{298}^{0}\right)$, potential barrier heights TSs $\left(\Delta E^{\mathrm{TS}}\right)$ with zero-point energy (ZPE) corrections at the $\mathrm{T}_{1}$ state at the B3LYP/6-311+G(d,p) level of the 9 reaction channels, and the reaction channel forming PTAIC1 at the $S_{0}$ state together with the bond breaking dissociation energies of the corresponding reactants (all in eV)

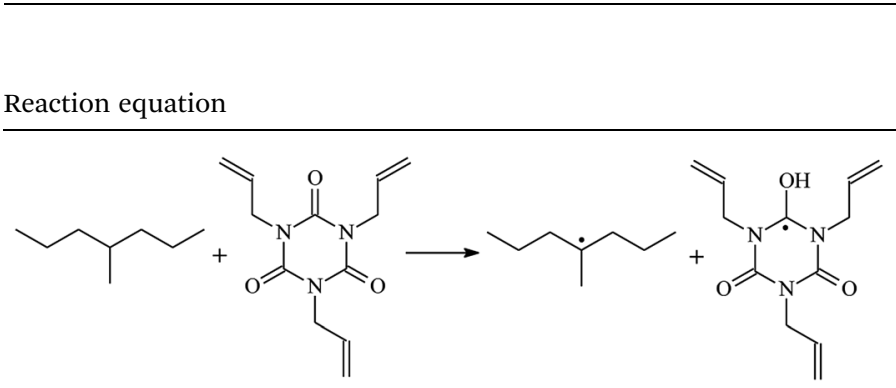

B3LYP/6-311+G(d,p)<smiles>C=CCN1C(=O)N(CC=C)C(=O)N(CC=C)N(CC=C)C1=O</smiles><smiles></smiles>

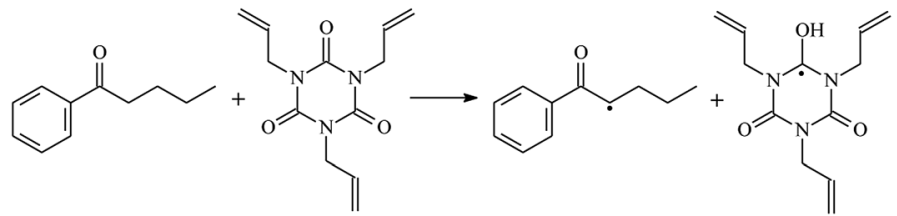<smiles>C=CCN1C(=O)N(CC=C)C(=O)N(CC=C)N(CC=C)C1=O</smiles><smiles>C=CCN1C(=O)N(CC=C)C(=O)N(CC=C)N(CC=C)C1=O</smiles><smiles></smiles><smiles></smiles> 
B3LYP/6-311+G(d,p)

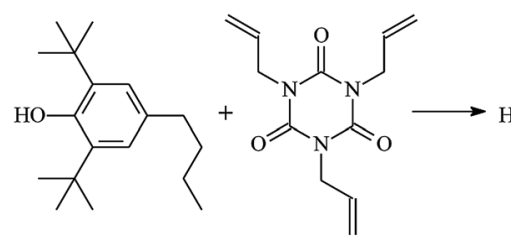<smiles></smiles>

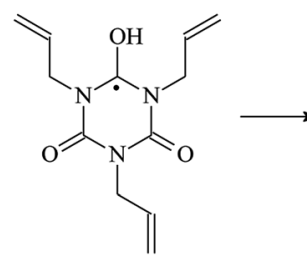<smiles>C=CCn1c(=O)n(CC=C)c(=O)n(CCC)c1=O</smiles>

benzene ring molecules possess stronger capability of trapping electrons than that of an aliphatic chain. They also possess lower IP than Pe and give rise to collision ionization before the polyethylene chain is ionized. This can prevent the degradation of the polymer matrix when they are present in XLPE insulation composite products, which is consistent with Ashcraft's suggestion. ${ }^{7}$ They can trap the hot electron and decrease the kinetic energy of the hot electron so that the hot electron does not have enough energy to break the $\mathrm{C}-\mathrm{C}$ bonds of XLPE. In addition, they can also decrease $E_{\mathrm{g}}$ with a decrease in transition energy, where the electronic transition dissipates the hot electron energy and prevents degradation of the polymer matrix. As a result, they can effectively inhibit the initiation and propagation of electrical treeing in XLPE and simultaneously strengthen the electrical breakdown strength that XLPE can endure. Furthermore, the insulating XLPE material exhibits an elevated AC breakdown strength.

\subsection{Energetics and mechanism}

The reaction enthalpies at $298 \mathrm{~K}\left(\Delta H_{298}^{0}\right)$ and the potential barrier heights $\left(\Delta E^{\mathrm{TS}}\right)$ with zero-point energy (ZPE) corrections at the $\mathrm{T}_{1}$ state or $\mathrm{S}_{0}$ state obtained for the 10 reaction channels at the B3LYP/6-311+G(d,p) level, as well as the relative bond breaking dissociation energies $\left(D_{298}^{0}\right)$, are listed in Table 4 . The bond breaking dissociation energies are closely related to the corresponding reaction potential barrier heights. The calculated result shows that the bond dissociation energy of the $\mathrm{H}$ atom in the hydroxyl of the antioxidant $\mathrm{Bp}(3.12 \mathrm{eV})$ is lower than that of the $\mathrm{H}$ atom in alkyl H-Bp4 $3.56 \mathrm{eV}$ (or Bp3 $4.06 \mathrm{eV}$ and Bp2 $4.05 \mathrm{eV}$ ). This means that antioxidants are often used to kill free radicals in XLPE insulation materials for use in high voltage cables. Herein, we aim to investigate the possibility of the radical formation of $\mathrm{Vp}$ and Bp compared with Pe during the process of producing UV radiation cross-linking polyethylene insulation materials for high voltage cables. The calculated $\Delta E^{T_{1}-S_{0}}$ (the relative energy margins between the $S_{0}$ and $T_{1}$ states) at the QCISD(T)//B3LYP level of acetophenone was 74.92 kcal mol ${ }^{-1}$ in our previous study, ${ }^{17}$ which is consistent with the reported experimental value of $73.74 \mathrm{kcal} \mathrm{mol}^{-1} .^{25}$ The calculated $\Delta E^{\mathrm{T}_{1}-\mathrm{S}_{0}}$ at the $\operatorname{QCISD}(\mathrm{T}) / 6-311+\mathrm{G}(3 \mathrm{df}, 2 \mathrm{p}) / / \mathrm{B} 3 \mathrm{LYP} / 6-$ $311+\mathrm{G}(\mathrm{d}, \mathrm{p})$ level of benzophenone is $2.95 \mathrm{eV}$ in this study, which is in good agreement with the experimental value of 24224 $\mathrm{cm}^{-1}(3.00 \mathrm{eV})$ reported by Ito and co-workers. ${ }^{25}$ During the UV radiation cross-linking process, benzophenone is excited from the ground state $S_{0}$ to the singlet excited state $S_{1}$ and then transformed into the triplet excited state $\mathrm{T}_{1}$ through ISC. Benzophenone at the $\mathrm{T}_{1}$ state initiates a hydrogen abstraction reaction with $\mathrm{Pe}, \mathrm{Vp}$, or Bp to form the corresponding radicals. The initiation behavior of benzophenone was explored in detail in our previous study. ${ }^{34}$ Under the action of UV-light and benzophenone photosensitizer, TAIC at the $\mathrm{T}_{1}$ state reacts with $\mathrm{Pe}, \mathrm{Vp}$, and $\mathrm{Bp}$. The reaction potential barrier for the formation of Pe2 by benzophenone is $0.20 \mathrm{eV}{ }^{34}$ whereas the reaction potential barrier for the formation of Pe2 by TAIC is $1.70 \mathrm{eV}$ in this study. PTAIC transports electrons and protons from PTAIC1 via TS quickly with the reaction potential barrier of $0.66 \mathrm{eV}$, the double bond opens in PTAIC through intra-molecular isomerization reaction, and the PTAIC1 radical cross-links with the PE radical at three reaction sites, where the multiplication crosslinking effect is present. This is the reason that the UV radiation cross-linking reaction of polyethylene is initiated by benzophenone, and the multi-functional cross-linker TAIC needs to take part in the cross-linking process. For the 9 radical forming reactions by TAIC, the reaction potential barrier for the formation of Pe2 is close to that for $\mathrm{Vp} 2$ and $\mathrm{Bp} 2$. This means that it is possible to form $\mathrm{Vp} 2$ and Bp2 when forming Pe2. Specifically, the polyethylene molecule chain radical Pe2 not only reacts with other Pe2 to form XLPE, but also works with the voltage stabilizer $\mathrm{Vp} 2$ and the antioxidant $\mathrm{Bp} 2$ to yield inactive products. Thus, the voltage stabilizer and antioxidant can graft to the polyethylene chain in the UV radiation cross-linking process. The reaction channel $\mathrm{RVp} 2$ is easier than $\mathrm{RPe} 2$ due to the larger electronegativity of $\mathrm{O}$ than that of $\mathrm{C}$ and the aromatic 
ketone of Vp2 exhibits a conjugated effect. The potential barriers of the reaction channel RBp4 are smaller than that of the corresponding reaction channel $\mathrm{RPe} 4$ because the bond breaking dissociation energy in $\mathrm{Bp} 4$ is $3.56 \mathrm{eV}$, which is smaller than that of $3.91 \mathrm{eV}$ in $\mathrm{Pe} 4$. Therefore, the $\mathrm{H}$ in $\mathrm{Bp} 4$ can dissociate easily which leads to more facile $\mathrm{Bp} 4$ radicals with lower energy barriers. The reactions of the benzophenone initiated PE radicals are exothermic, as stated in ref. 34, which would promote the cross-linking reactions by TAIC further with an increase in temperature up to $180{ }^{\circ} \mathrm{C}$ according to the production process. Therefore, the cross-linkable polyethylene is only cross-linked by UV radiation with the benzophenone photoinitiator with a rate on the minute timescale, whereas the rate is on the second timescale in the presence of TAIC. Vp may be effective as a voltage stabilizer in real applications to increase the breakdown strength of insulating XLPE materials since it can be bonded to the polyethylene chain via the UV radiation crosslinking process. New experimental efforts are required to optimize the polyethylene UV radiation cross-linking process and develop insulation materials for high-voltage cables that can withstand more than $500 \mathrm{kV}$ in real applications.

\section{Conclusion}

A systematic theoretical study on the TAIC multiplication and acceleration of the cross-linking reaction mechanisms in the polyethylene UV radiation cross-linking process has been carried out at the atomic and molecular levels. The reason why benzophenone initiates the radical reaction and TAIC accelerates the cross-linking reaction has been explained. Aromatic ketone voltage stabilizer $\mathrm{Vp}$ and hindered phenol antioxidants Bp molecules can be bonded to the polyethylene chain during the polyethylene UV radiation cross-linking process based on the correlating reaction potential barrier analysis, where it is favorable to tolerate a local high electric field. The suggested mechanism may provide reliable information to optimize the UV radiation cross-linking process, to select photoinitiators, cross-linkers, and antioxidants, and design the perfect voltage stabilizer for real applications.

\section{Acknowledgements}

We thank Professor Tierui Zhang (Key Laboratory of Photochemical Conversion and Optoelectronic Materials, Technical Institute of Physics and Chemistry (TIPC), Chinese Academy of Sciences (CAS), Beijing 100190, China) for his fruitful discussions and checking English. This study is supported by the National Basic Research Program of China (2012CB723308), and the National Natural Science Foundation of China (51337002, 21201059 and 50977019).

\section{References}

1 B. Qu and B. Rånby, Photocross-linking of Low-density Polyethylene. I. Kinetics and Reaction Parameters, J. Appl. Polym. Sci., 1993, 48, 701-709.
2 B. Qu, W. Bao, Q. Wu and W. Shi, Recent Developments on Photoinitiated Crosslinking of Polyethylene and Its Applications for Manufacturing Insulated Wire and Cable, IEEE International Conference on the Properties and Applications of Dielectric Materials, Harbin, 2009, pp. 33-36.

3 Y. Qing and B. Rånby, Photoinitiated Crosslinking of Low Density Polyethylene. IV: Continuous Extrusion Application, Polym. Eng. Sci., 1992, 32, 831-835.

$4 \mathrm{Q}$. $\mathrm{Wu}$ and B. Qu, Photoinitiating Characteristics of Benzophenone Derivatives as New Initiators in the Photocrosslinking of Polyethylene, Polym. Eng. Sci., 2001, 41, 1220-1226.

5 Y. Qing, W. Xu and B. Rånby, Photoinitiated Crosslinking of Low Density Polyethylene I: Reaction and Kinetics, Polym. Eng. Sci., 1991, 31, 1561-1566.

6 B. Qu, W. Shi and B. Rånby, Studies of Photocrosslinking of Polyethylene in the Melt, Polym. Mater.: Sci. Eng., 1990, 6, 3743.

7 A. C. Ashcraft, R. M. Eichhorn and R. G. Shaw, Laboratory Studies of Treeing in Solid Dielectrics and Voltage Stabilization of Polyethylene, IEEE Int. Symp. Electr. Insul., Conf. Rec., 1976, 6.

8 M. Jarvid, A. Johansson, V. Englund, A. Lundin, S. Gubanski, C. Müller and M. R. Andersson, High Electron Affinity: A Guiding Criterion for Voltage Stabilizer Design, J. Mater. Chem. A, 2015, 3, 7273-7286.

9 Y. Yamano and H. Endoh, Increase in Breakdown Strength of PE Film by Additives of Azocompounds, IEEE Trans. Dielectr. Electr. Insul., 1998, 5, 270-275.

10 Y. Yamano, Roles of Polycyclic Compounds in Increasing Breakdown Strength of LDPE Film, IEEE Trans. Dielectr. Electr. Insul., 2006, 13, 773-781.

11 Y. Yamano and M. Iizuka, IEEE Trans. Dielectr. Electr. Insul., 2009, 16, 189-198.

12 V. Englund, R. Huuva and S. M. Gubanski, IEEE Trans. Dielectr. Electr. Insul., 2009, 16, 1455-1460.

13 M. Jarvid, A. Johansson, V. Englund, S. Gubanski and M. R. Andersson, Electrical Tree Inhibition by Voltage Stabilizers, Annual Repot Conference on Electrical Insulation and Dielectric Phenomena, October 2012, pp. 605-608.

14 M. Jarvid, A. Johansson, J. M. Bjuggren, H. Wutzel, V. Englund, S. Gubanski, C. Müller and M. R. Andersson, Tailored Side-Chain Architecture of Benzil Voltage Stabilizers for Enhanced Dielectric Strength of CrossLinked Polyethylene, J. Polym. Sci., Part B: Polym. Phys., 2014, 52, 1047-1054.

15 H. Zhang, Y. Shang, H. Zhao, B. Z. Han and Z. S. Li, Study of the Effect of Valence Bond Isomerizations on Electrical Breakdown by Adding Acetophenone to Polyethylene as Voltage Stabilizers, Comput. Theor. Chem., 2015, 1062, 99104.

16 H. Zhang, Y. Shang, H. Zhao, B. Z. Han and Z. S. Li, Mechanisms on Inhibition of Polyethylene Electrical Tree Aging: A Theoretical Study, J. Mol. Model., 2013, 19, 30353044 .

17 H. Zhang, Y. Shang, H. Zhao, B. Z. Han and Z. S. Li, Mechanisms on Electrical Breakdown Strength Increment 
of Polyethylene by Acetophenone and its Analogues Addition: A Theoretical Study, J. Mol. Model., 2013, 19, 4477-4485.

18 H. Zhang, Y. Shang, X. Wang, H. Zhao, B. Z. Han and Z. S. Li, Mechanisms on Electrical Breakdown Strength Increment of Polyethylene by Aromatic Carbonyl Compounds Addition: A Theoretical Study, J. Mol. Model., 2013, 19, 5429-5438.

19 R. G. Parr and W. Yang, Density-functional Theory of Atoms and Molecules, Oxford University Press: New York, 1989.

20 Ó. Rubio-Pons, O. Loboda, B. Minaev, B. Schimmelpfennig, O. Vahtras and H. Ågren, CASSCF Calculations of Tripletstate Properties. Applications to Benzene Derivatives, Mol. Phys., 2003, 101, 2103-2114, An International Journal at the Interface Between Chemistry and Physics.

21 B. F. Minaev, S. Knuts, H. Ågren and O. Vahtras, The Vibronically Induced Phosporescence in Benzene, Chem. Phys., 1993, 175, 245-254.

22 S. Aloïse, C. Ruckebusch, L. Blanchet, J. Réhault, G. Buntinx and J. P. Huvenne, The Benzophenone $S_{1}\left(n, \pi^{*}\right) \rightarrow T_{1}\left(n, \pi^{*}\right)$ States Intersystem Crossing Reinvestigated by Ultrafast Absorption Spectroscopy and Multivariate Curve Resolution, J. Phys. Chem. A, 2008, 112, 224-231.

23 L. Favero, G. Granucci and M. Persicob, Surface Hopping Investigation of Benzophenone Excited State Dynamics, Phys. Chem. Chem. Phys., 2016, 18, 10499-10506.

24 G. Spighi, M. A. Gaveau, J. M. Mestdagh, L. Poisson and B. Soep, Phys. Chem. Chem. Phys., 2014, 16, 9610-9618.

25 N. Ohmori, T. Suzuki and M. Ito, Why Does Intersystem Crossing Occur in Isolated Molecules of Benzaldehyde, Acetophenone, and Benzophenone?, J. Phys. Chem., 1988, 92, 1086-1093.

26 W. H. Fang, Ab Initio Determination of Dark Structures in Radiationless Transitions for Aromatic Carbonyl Compounds, Acc. Chem. Res., 2008, 41, 452-457.

27 T. N. Truong, W. T. Duncan and R. L. Bell, Chemical Applications of Density-Functional Theory. American Chemical Society, Washington, DC, 1996, p. 85.
28 C. Lee, W. Yang and R. G. Parr, Development of the ColleSalvetti Conelation Energy Formula into a Functional of the Electron Density, Phys. Rev. B, 1988, 37, 785-789.

29 B. Miehlich, A. Savin, H. Stoll and H. Preuss, Results Obtained with the Correlation Energy Density Functionals of Becke and Lee, Yang and Parr, Chem. Phys. Lett., 1989, 157, 200-206.

30 A. D. Becke, Density-functional Thermochemistry. III. The Role of Exact Exchange, J. Chem. Phys., 1993, 98, 5648-5652.

31 M. J. Frisch, G. W. Trucks, H. B. Schlegel, G. E. Scuseria, M. A. Robb, J. R. Cheeseman, G. Scalmani, V. Barone, B. Mennucci, G. A. Petersson, H. Nakatsuji, M. Caricato, X. Li, H. P. Hratchian, A. F. Izmaylov, J. Bloino, G. Zheng, J. L. Sonnenberg, M. Hada, M. Ehara, K. Toyota, R. Fukuda, J. Hasegawa, M. Ishida, T. Nakajima, Y. Honda, O. Kitao, H. Nakai, T. Vreven, J. A. Montgomery Jr, J. E. Peralta, F. Ogliaro, M. Bearpark, J. J. Heyd, E. Brothers, K. N. Kudin, V. N. Staroverov, R. Kobayashi, J. Normand, K. Raghavachari, A. Rendell, J. C. Burant, S. S. Iyengar, J. Tomasi, M. Cossi, N. Rega, J. M. Millam, M. Klene, J. E. Knox, J. B. Cross, V. Bakken, C. Adamo, J. Jaramillo, R. Gomperts, R. E. Stratmann, O. Yazyev, A. J. Austin, R. Cammi, C. Pomelli, J. W. Ochterski, R. L. Martin, K. Morokuma, V. G. Zakrzewski, G. A. Voth, P. Salvador, J. J. Dannenberg, S. Dapprich, A. D. Daniels, O. Farkas, J. B. Foresman, J. V. Ortiz, J. Cioslowski and D. J. Fox, Revision A.02, Gaussian, Inc., Wallingford CT, 2009. 32 S. G. Lias, R. D. Levin, S. A. Kafafi and J. E. Bartmess, in NIST ChemistryWebBook, NIST Standard Reference Database Number 69, 2016.

33 H. Zhang, Y. Shang, M. X. Li, H. Zhao, X. Wang and B. Z. Han, Theoretical Study on the Radical Reaction Mechanism in the Cross-linking Process of Polyethylene, RSC Adv., 2015, 5, 90343-90353.

34 H. Zhang, Y. Shang, M. X. Li, H. Zhao, X. Wang and B. Z. Han, Theoretical study on the reaction mechanism in the UV radiation cross-linking process of polyethylene, $R S C$ $A d v .$, 2016, 6, 110831-110839. 